\title{
Ácido fumárico e sua combinação com ácido lático ou propionato de cálcio em dietas de leitões recém-desmamados
}

\author{
[Fumaric acid associated with lactic acid or calcium propionate for weaning piglet diets] \\ F.E. Gomes ${ }^{1}$, D.O. Fontes ${ }^{2 *}$, C.H.F. Vasconcellos ${ }^{3}$, F.C.O. Silva ${ }^{4}$ \\ ${ }^{1}$ Centro de Ciências Agrárias, UFRR - Boa Vista, RR \\ ${ }^{2}$ Escola de Veterinária - UFMG \\ Caixa Postal 567 \\ 30123-970 - Belo Horizonte, MG \\ ${ }^{3}$ Instituto Federal de Mato Grosso - Cuiabá, MT \\ ${ }^{4}$ Pesquisador Epamig - Viçosa, MG
}

\begin{abstract}
RESUMO
Avaliou-se o efeito da adição dos ácidos fumárico, lático e propionato de cálcio ou suas combinações sobre o desempenho, pH estomacal, $\mathrm{pH}$ duodenal, morfologia e morfometria do intestino delgado de leitões desmamados aos 15 dias de idade. Foram utilizados 180 leitões, 90 machos castrados e 90 fêmeas, com média de peso inicial de 4,78 $\pm 1,19 \mathrm{~kg}$, distribuídos em delineamento de blocos ao acaso. Utilizaramse cinco tratamentos: T1 - ração controle (RC); T2 - RC + 0,5\% de ácido fumárico; T3 - RC + 0,5\% de ácido fumárico $+1,0 \%$ de propionato de cálcio; T4 - RC + 0,5\% de ácido fumárico + 1,0\% de ácido lático; T5 - RC + 0,5\% de ácido fumárico + 0,5\% de propionato de cálcio + 0,5\% de ácido lático, com seis repetições e seis animais por unidade experimental. Não houve influência $(P>0,05)$ dos tratamentos sobre o ganho de peso diário (GPD), consumo de dieta diário (CRD) e conversão alimentar (CA). Quanto ao epitélio intestinal, não houve diferenças $(\mathrm{P}>0,05)$ entre tratamentos em relação à altura do epitélio do duodeno, jejuno e íleo. Não houve efeito dos tratamentos $(\mathrm{P}>0,05)$ sobre o $\mathrm{pH}$ do estômago e do jejuno. A inclusão do ácido fumárico não influenciou o desempenho dos leitões.
\end{abstract}

Palavras chave: leitão, ácidos orgânicos, desempenho, intestino delgado

\begin{abstract}
This assay was carried out to evaluate the effect of fumaric acid; latic acid and calcium propionate on the performance and morphological and morphometric characteristics of small intestine in weaning piglets. A total of 180 weaning piglets were used (90 males and 90 females) with 15 days of age and an initial weight of $4.781 .1 \mathrm{~kg}$, distributed in a completely randomized block designed with five treatments: T1 Control ration (CR); T2 - CR + 0.5\%fumaric acid; T3 - CR + 0.5\% fumaric acid + $1.0 \%$ calcium propionate; $\mathrm{T} 4-\mathrm{CR}+0.5 \%$ fumaric acid $+1.0 \%$ lactic acid; $\mathrm{T} 5-\mathrm{CR}+0.5 \%$ fumaric acid $+0.5 \%$ calcium propionate $+0.5 \%$ lactic acid , six replicates of six animals. The performance, morphological and morphometric characteristics of small intestine were evaluated. Daily weight gain, daily feed intake, weight gain: feed intake ratio was not affected by treatments. Significant differences between treatments were not observed for intestinal epithelium height of duodenum, jejunum and ileum (P>0.05). No significant differences between treatments were observed $(P<0.05)$ for the $p H$ of stomach and jejunum. No effect of fumaric acid on piglets performance was observed.
\end{abstract}

Keywords: organic acid, performance, piglet, small intestine, morphology

Recebido em 23 de dezembro de 2009

Aceito em 19 de abril de 2011

*Autor para correspondência (corresponding author)

E-mail: dalton@vet.ufmg.br 


\section{INTRODUÇÃo}

A indústria suinícola tem adotado como prática rotineira a redução da idade de desmame dos leitões, buscando melhoria no desempenho e mais produtividade das matrizes. No entanto, o processo de desmame consiste em um severo fator de estresse para os leitões jovens, não somente por eles serem separados das mães e removidos para novas baias com novos companheiros, mas também por eles terem de se acostumar a comer alimento sólido com uma composição diferente do leite materno (McCracken et al., 1995).

Diante das mudanças enfrentadas pelos leitões, neste período, os riscos de distúrbios digestivos acentuam-se. É comum o aparecimento de diarreias e alterações estruturais nas vilosidades intestinais, afetando, consequentemente, o desempenho dos animais. Outro fato importante consiste na capacidade limitada dos leitões produzirem ácido clorídrico $(\mathrm{HCl})$ no estômago. Durante a lactação, a falta de acidez é suprida pela produção de ácido lático a partir da fermentação da lactose, pela ação dos lactobacilos. Após o desmame, a quantidade de lactose diminui e a capacidade tamponante do conteúdo digestivo aumenta. Como consequência, o pH sobe, provocando digestão insuficiente da proteína (Easter, 1988). Ocorre, ainda, a chegada massiva de patógenos ao intestino delgado, havendo necessidade de se ter uma barreira protetora (Mayes, 1990).

Como estratégia nutricional, antibióticos são adicionados às dietas pós-desmame para controlar estes problemas. Sabe-se, contudo, que o uso de antibióticos promotores de crescimento está sendo banido e que alternativas estão sendo testadas por pesquisadores. Dentre os aditivos estudados, os ácidos orgânicos e seus sais têm sido mais aceitos pelos fabricantes de rações, produtores e consumidores.

Aumento da taxa de crescimento pós-desmame e eficiência na utilização da dieta têm sido conseguidos pela suplementação às dietas de leitões com ácidos orgânicos puros ou suas misturas e/ou seus sais (Ravindran e Kornegay, 1993; Kyriakis et al., 1996). Essa melhora no desempenho está relacionada ao abaixamento do $\mathrm{pH}$ gástrico e à subsequente modificação da microflora intestinal por estes ácidos (Scipioni et al., 1978). Sabe-se também que o efeito deles sobre o desempenho varia (Partanen e Mroz, 1999). Neste sentido, o presente trabalho teve o objetivo de avaliar o uso dos ácidos fumárico, lático e propionato de cálcio ou suas combinações, sobre o desempenho, $\mathrm{pH}$ estomacal, $\mathrm{pH}$ duodenal, morfologia e morfometria do intestino delgado de leitões desmamados aos 15 dias.

\section{MATERIAL E MÉTODOS}

O experimento foi realizado em janeiro/fevereiro de 2006. Os animais foram alojados em creche dotada de baias suspensas providas de comedouros semiautomáticos e de bebedouros tipo chupeta, em galpão de alvenaria com piso de concreto com uma parte ripada, coberto com telhas de barro tipo francesa. Cada animal dispunha de uma área de $0,33 \mathrm{~m}^{2}$. O alojamento ocorreu após as instalações serem lavadas e desinfetadas e permanecerem vazias por três dias. Foi utilizado um termômetro de máxima e mínima no interior de cada sala da creche para registro diário da temperatura. As temperaturas mínimas e máximas verificadas no período foram, respectivamente, $25,8 \pm 1,2^{\circ} \mathrm{C}$ e $27,0 \pm 0,8^{\circ} \mathrm{C}$.

Foram utilizados 180 leitões de linhagem comercial, selecionados geneticamente para alta deposição de carne magra na carcaça, desmamados aos 15 dias de idade, com peso inicial de $4,78 \pm 1,19 \mathrm{~kg}$. Por ocasião do desmame, foram pesados e distribuídos uniformemente nas unidades experimentais. Os animais receberam ração e água à vontade. $\mathrm{O}$ delineamento experimental utilizado foi o de blocos ao acaso, com cinco tratamentos, seis repetições e seis animais por unidade experimental, sendo três machos e três fêmeas. Na formação de blocos, foi considerado como critério o peso inicial. Aos 38 dias de idade, três animais por tratamento foram abatidos para medição do $\mathrm{pH}$ do estômago e duodeno, e coleta de segmentos do intestino delgado - duodeno, jejuno e íleo - destinados às avaliações morfológicas e morfométricas.

As dietas experimentais, isoenergéticas e isoproteicas (Tab. 1) foram formuladas para exceder as exigências de suínos na fase préinicial, de acordo com NRC (Nutrient...1998). As dietas experimentais foram produzidas a partir de uma dieta basal $\left(\mathrm{T}_{1}\right)$ contendo $20,4 \%$ de 
proteína e 3400kcal/kg de energia metabolizável, composta de milho moído, farelo de soja, açúcar, óleo de soja, inerte (caulim), concentrado 40\% e aminoácidos sintéticos.

As dietas fornecidas e as sobras foram pesadas aos 14, 21 e 38 dias de idade para determinação do consumo de dieta, ganho de peso e conversão alimentar. As sobras e os desperdícios de ração foram pesados e deduzidos do total de ração fornecida. Foram determinados o ganho de peso diário (GPD), o consumo de ração diário (CRD) e a conversão alimentar (CA).

Dos 15 aos 38 dias, os leitões receberam: T1 - ração controle (sem adição de acidificante); T2 - ração controle + 0,5\% de ácido fumárico); T3 - ração controle $+0,5 \%$ de ácido fumárico + $1 \%$ de propionato de cálcio; T4 - ração controle + 0,5\% de ácido fumárico + 1\% de ácido lático; T5 - ração controle $+0,5 \%$ de ácido fumárico + $0,5 \%$ de propionato de cálcio $+0,5 \%$ de ácido lático.

Após a preparação, coletaram-se amostras das dietas para futuras análises e determinou-se, ainda, o pH delas. Essa determinação foi feita usando-se uma amostra de 10 gramas de cada dieta, diluída em 30mL de água bidestilada e deionizada e agitada em agitador elétrico tipo shaker, por 30 minutos, até a obtenção de um conteúdo homogêneo. A leitura do $\mathrm{pH}$ foi feita utilizando-se um peagâmetro digital Quimis ${ }^{\circledR}$.

A determinação do $\mathrm{pH}$ do conteúdo do estômago e do jejuno foi feita imediatamente após o abate, por uma incisão nos segmentos e introdução do sensor do peagâmetro. Posteriormente, foi retirado um fragmento fechado, com aproximadamente $2 \mathrm{~cm}$ de comprimento, do duodeno, do jejuno e do íleo. O do duodeno foi a $10 \mathrm{~cm}$ da inserção com o estômago, e o do jejuno correspondente a $50 \%$ do comprimento do intestino delgado. Foram, então, imediatamente lavados em água destilada, identificados e fixados em solução de formol tamponado $10 \%$ para futuras análises. As amostras foram preparadas de acordo com a técnica descrita por Junqueira e Junqueira (1983), seguindo as etapas de desidratação, diafanização, inclusão em parafina, microtomia e coloração dos cortes. Foram confeccionadas duas lâminas por região coletada, com dois cortes cada. As análises morfométricas dos cortes histológicos foram realizadas em microscópio óptico, com aumento de 40 vezes. Para medição da altura do epitélio, utilizou-se analisador de imagem ImageproPlus 1.3.2.

Foi feita a determinação da ultraestrutura da mucosa intestinal por meio da microscopia eletrônica de varredura usando-se as amostras do duodeno, com aproximadamente $2 \mathrm{~cm}$ de comprimento, extraídas de cada leitão abatido. Fragmentos de $0,5 \mathrm{~cm}$ foram fixados por 24 horas a $4^{\circ} \mathrm{C}$ em glutaraldeído $2,5 \%$ em tampão fosfato $(0,1 \mathrm{M}, \mathrm{pH} 7,4)$ e pós-fixados em tetróxido de ósmio $1 \%$ por duas horas. Posteriormente, os fragmentos foram desidratados em série de concentrações crescentes de etanol (70 a 100\%). Após a desidratação, as amostras foram submetidas à obtenção do ponto crítico de secagem, utilizando-se $\mathrm{CO}_{2}$ (aparelho Bal-Tec), montadas em suporte, metalizadas com ouro paládio em aparelho Denton Vacum Desk II e observadas em microscópio eletrônico de varredura (Jeol-JSM 5410). Para observação das vilosidades, as amostras foram eletronmicrografadas.

Os dados de desempenho, $\mathrm{pH}$ e das análises morfométricas foram submetidos a análises de variância utilizando-se o pacote estatístico computacional SAEG (Sistemas..., 2000) e as médias dos tratamentos comparadas pelo teste SNK a 5\% de probabilidade.

\section{RESULTADOS E DISCUSSÃO}

Os resultados de ganho de peso médio diário (GPD), consumo de ração médio diário (CRD) e conversão alimentar (CA) são apresentados na Tab. 2.

Os tratamentos não influenciaram $(\mathrm{P}>0,05) \quad 0$ peso final, o ganho de peso diário (GPD), o consumo de ração diária (CRD) e a conversão alimentar (CA). Resultados semelhantes foram encontrados por Giesting e Easter (1985), ao trabalharem com ácido propiônico em dietas de leitões desmamados. Silva et al. (2002) não observaram efeito significativo da adição de ácidos orgânicos - fumárico, lático e propionato de cálcio -, quando utilizados isoladamente, sobre o desempenho de leitões, entretanto, 
segundo esses autores, as combinações de ácidos - fumárico + propionato de cálcio e lático + propionato de cálcio - proporcionaram melhora do desempenho dos animais.

Vários pesquisadores observaram efeito de ácidos orgânicos quando utilizados isoladamente em dietas de leitões. Tsiloyannis et al. (2001) verificaram melhora significativa $(\mathrm{P}<0,05)$ no desempenho de leitões desmamados aos 21, 25 e 28 dias, respectivamente, quando foram alimentados com dietas que continham 1,6\% de ácido lático. Tsiloyannis et al. (2001), ao adicionarem ácido propiônico (1,0\%) em dietas de leitões desmamados, também verificaram melhora nos parâmetros de desempenho. Silveira (2004), ao avaliar diferentes proporções - 0,5; 1,0; 1,5 e 2,0\% - de ácido fumárico adicionado às dietas de leitões desmamados aos 20 dias de idade, verificou que, do desmame aos 28 dias de idade, não houve efeito sobre o desempenho. No entanto, dos 29 aos 38 dias de idade, os animais responderam negativamente à inclusão do ácido em proporções crescentes. De maneira semelhante, Silva et al. (2006) e Martins et al. (2006) também não observaram efeito do uso de acidificantes sobre os parâmetros de desempenho de leitões recém-desmamados, diferente de Gomes et al. (2007), que verificaram que o uso de dietas suplementadas com ácido fumárico a 0,5\% para leitões recém-desmamados melhorava o desempenho dos animais nas duas primeiras semanas pós-desmame. Esses mesmos autores observaram que a associação do ácido fumárico (1,0\%) + ácido fórmico (0,5\%) diminuía o ganho de peso diário dos leitões dos 15 aos 36 dias de idade.

Tabela 1. Composição percentual das dietas experimentais usadas para suínos recém-desmamados

\begin{tabular}{|c|c|c|c|c|c|}
\hline Ingrediente & $\mathrm{T}_{1}$ & $\mathrm{~T}_{2}$ & $\mathrm{~T}_{3}$ & $\mathrm{~T}_{4}$ & $\mathrm{~T}_{5}$ \\
\hline Milho (7,8\% PB) & 24,838 & 24,838 & 24,838 & 24,838 & 24,838 \\
\hline Farelo de soja (46\% PB) & 24,2 & 24,2 & 24,2 & 24,2 & 24,2 \\
\hline Caulim & 1,7 & 1,2 & 0,2 & 0,02 & 0,11 \\
\hline Açúcar & 6 & 6 & 6 & 6 & 6 \\
\hline Óleo de soja refinado & 3,2 & 3,2 & 3,2 & 3,2 & 3,2 \\
\hline Concentrado $^{1} 40 \%$ & 40 & 40 & 40 & 40 & 40 \\
\hline DL-metionina 99\% & 0,014 & 0,014 & 0,014 & 0,014 & 0,014 \\
\hline L-treonina 98\% & 0,048 & 0,048 & 0,048 & 0,048 & 0,048 \\
\hline Ácido fumárico & - & 0,5 & 0,5 & 0,5 & 0,5 \\
\hline Propionato de cálcio & & & 1 & - & 0,5 \\
\hline Ácido lático (85\%) & & & & 1,18 & 0,59 \\
\hline Total $(\mathrm{kg})$ & 100,00 & 100,00 & 100,00 & 100,00 & 100,00 \\
\hline \multicolumn{6}{|c|}{ Valor nutricional calculado ${ }^{2}$ (\% na MN) } \\
\hline Energia metabolizável (kcal/kg) & 3400 & 3400 & 3400 & 3400 & 3400 \\
\hline Proteína bruta (\%) & 20,45 & 20,45 & 20,45 & 20,45 & 20,45 \\
\hline Cálcio (\%) & 0,57 & 0,57 & 0,57 & 0,57 & 0,57 \\
\hline Fósforo disponível & 0,47 & 0,47 & 0,47 & 0,47 & 0,47 \\
\hline Lisina total $(\%)$ & 1,56 & 1,56 & 1,56 & 1,56 & 1,56 \\
\hline Metionina + cistina total (\%) & 0,88 & 0,88 & 0,88 & 0,88 & 0,88 \\
\hline Treonina total (\%) & 1,01 & 1,01 & 1,01 & 1,01 & 1,01 \\
\hline Triptofano total (\%) & 0,25 & 0,25 & 0,25 & 0,25 & 0,25 \\
\hline
\end{tabular}

${ }^{1}$ Composição e níveis de garantia (por kg do produto): farelo de soja (48\% PB), 399,38g; soro de leite, 140,60g; leite pó integral, 100,00g; lactose pura, 100,00g; resíduos de biscoito, 62,00g; farinha de peixe $67 \%$ PB, 50,00g; fosfato bicálcico, 44,00g; protenose (60\% PB), 30,00g; sipernat 22 (MC), 15,00g; sal comum, 8,00g; calcário do micro, 13,01g; L-lisina 80 (MI), 9,31g; óxido de zinco (79\% Zn), 7,57g; cloreto de colina 60\% - MI, 3,03g; sulfato colistina 8\%, 2,50g; seldox dry (MI), 0,50g. biotina 1,5mg; ácido fólico 3mg; ácido pantotenico 105mg; cobalto 0,49mg; vitamina A 40.500ui/kg; aditivo antioxidante 312mg; vitamina D3 8.100 ui/kg; vitamina $K_{3} 18 \mathrm{mg}$; selênio 1 ,9mg; colina 1.800mg; promotor de crescimento 750mg; ferro 344mg; vitamina $\mathrm{B}_{12}$ 150mcg ;vitamina B1 6mg; vitamina E 181ui/kg; zinco 6.250mg; niacina 150mg; Iodo 3,81mg; vitamina B6 12mg; manganês 129mg; vitamina B2 18mg; cálcio (máx) 5\%; fósforo (mín) 1\%; extrato etéreo (mín) 1,5\%; matéria fibrosa (máx) 3\%; matéria mineral (máx) $16 \%$.

${ }^{2}$ Segundo Rostagno (2000). 
Tabela 2. Peso inicial (PI), peso final (PF), ganho de peso médio diário (GPD), consumo de ração médio diário (CRD) e conversão alimentar (CA) de leitões aos 38 dias de idade, e que consumiram dietas com diferentes combinações e proporções de inclusão de ácidos orgânicos

\begin{tabular}{|c|c|c|c|c|c|}
\hline Tratamento & PI (kg) & $\begin{array}{l}\mathrm{PF} \\
(\mathrm{kg})\end{array}$ & $\begin{array}{l}\text { GPD } \\
(\mathrm{g} / \mathrm{d})\end{array}$ & $\begin{array}{l}\text { CRD } \\
(\mathrm{g} / \mathrm{d})\end{array}$ & CA \\
\hline T1 Controle & 4,77 & 10,01 & 261 & 340 & 1,29 \\
\hline T2 Ácido fumárico (0,5\%) & 4,79 & 9,80 & 250 & 340 & 1,37 \\
\hline T3 Ácido fumárico (0,5\%) + Propionato de cálcio (1,0\%) & 4,79 & 10,39 & 280 & 348 & 1,25 \\
\hline T4 Ácido fumárico (0,5\%) + Ácido lático (1,0\%) & 4,76 & 9,46 & 234 & 300 & 1,28 \\
\hline $\begin{array}{l}\text { T5 Ácido fumárico }(0,5 \%)+\text { Propionato de cálcio }(0,5 \%)+ \\
\text { Ácido lático }(0,5 \%)\end{array}$ & 4,76 & 10,20 & 271 & 343 & 1,25 \\
\hline CV(\%) & & 6,65 & 12,86 & 11,48 & 7,66 \\
\hline
\end{tabular}

T1 - ração controle (sem adição de acidificante); T2 - ração controle + 0,5\% de ácido fumárico); T3 - ração controle + 0,5\% de ácido fumárico + 1\% de propionato de cálcio;T4 - ração controle + 0,5\% de ácido fumárico + 1\% de ácido lático; T5 - ração controle + 0,5\% de ácido fumárico + 0,5\% de propionato de cálcio + 0,5\% de ácido lático.

Os valores de $\mathrm{pH}$ das dietas experimentais $(\mathrm{pH}$ ração), conteúdo do estômago (pH estômago) e conteúdo do jejuno (pH jejuno) de leitões aos 38 dias de idade estão apresentados na Tab. 3. Não houve diferença entre os tratamentos $(\mathrm{P}>0,05)$ quanto ao $\mathrm{pH}$ das dietas acidificadas e $\mathrm{pH}$ do estômago e do jejuno.

Resultados semelhantes foram obtidos por várias pesquisas realizadas com objetivo de avaliar a influência de ácidos orgânicos dietéticos ou seus sais sobre os valores de $\mathrm{pH}$ nos diferentes segmentos do trato gastrintestinal e conteúdo da matéria seca estomacal (Partanen e Mroz, 1999). Ao trabalharem com ácido fumárico, Risley et al. (1991) e Gabert e Sauer (1995) também não encontraram diferenças entre os valores de $\mathrm{pH}$ nos diferentes segmentos do trato gastrintestinal.
Para Risley et al. (1992) e Bolduan et al. (1988), a adição de propionato de cálcio não influenciou $(\mathrm{P}>0,05)$ o $\mathrm{pH}$ do conteúdo estomacal e do jejuno. Mathew et al. (1991), ao trabalharem com ácido propiônico, observaram efeito significativo do ácido nessas avaliações. Variação nos resultados de medidas do $\mathrm{pH}$ do conteúdo gastrintestinal tem sido observada em vários estudos, provavelmente em função da região onde ocorreram as determinações, tipo de técnica utilizada e tempo após a última ingestão do alimento.

Os resultados de altura do epitélio $(\mu \mathrm{m})$ do duodeno, jejuno e íleo de leitões aos 38 dias de idade estão apresentados na Tab. 4.

Tabela 3. $\mathrm{pH}$ das dietas experimentais ( $\mathrm{pH}$ ração), do conteúdo do estômago (pH estômago) e do conteúdo do jejuno ( $\mathrm{pH}$ jejuno) de leitões aos 38 dias de idade, e que consumiram dietas com diferentes combinações e proporções de inclusão de ácidos orgânicos

\begin{tabular}{lrrr}
\hline Tratamento & pH ração & $\begin{array}{c}\mathrm{pH} \\
\text { estômago }\end{array}$ & $\begin{array}{c}\mathrm{pH} \\
\text { jejuno }\end{array}$ \\
\hline T1 Controle & 6,01 & 4,55 & 6,06 \\
T2 Ácido fumárico (0,5\%) & 5,48 & 4,13 & 5,86 \\
T3 Ácido fumárico (0, 5\%) + Propionato de cálcio (1,0\%) & 5,10 & 4,10 & 5,93 \\
T4 Ácido fumárico (0,5\%) + Ácido lático (1,0\%) & 4,58 & 4,23 & 5,83 \\
T5 Ácido fumárico (0,5\%) + Propionato de cálcio (0,5\%) + & 4,89 & 4,56 & 5,96 \\
Ácido lático (0,5\%) & & 12,63 & 5,91 \\
CV(\%)
\end{tabular}

T1 - ração controle (sem adição de acidificante); T2 - ração controle + 0,5\% de ácido fumárico); T3 - ração controle + 0,5\% de ácido fumárico $+1 \%$ de propionato de cálcio; T4 - ração controle $+0,5 \%$ de ácido fumárico $+1 \%$ de ácido lático; T5 - ração controle + 0,5\% de ácido fumárico + 0,5\% de propionato de cálcio + 0,5\% de ácido lático. 
Ácido fumárico e sua combinação...

Tabela 4. Altura do epitélio $(\mu \mathrm{m})$ do duodeno, do jejuno e do íleo de leitões aos 38 dias de idade, e que consumiram dietas com diferentes combinações e proporções de inclusão de ácidos orgânicos

\begin{tabular}{lccc}
\hline Tratamento & Duodeno & Jejuno & Íleo \\
\hline T1 Controle & $37,43 b$ & 29,50 & 27,10 \\
T2 Ácido fumárico (0,5\%) & $45,16 \mathrm{a}$ & 28,33 & 24,66 \\
T3 Ácido fumárico (0, 5\%) + Propionato de cálcio (1,0\%) & $46,46 a$ & 28,36 & 24,96 \\
T4 Ácido fumárico (0,5\%) + Ácido lático (1,0\%) & $46,33 a$ & 27,03 & 24,76 \\
T5 Ácido fumárico (0,5\%) + Propionato de cálcio (0,5\%) + & $40,40 \mathrm{a}$ & 26,00 & 24,73 \\
Ácido lático (0,5\%) & & & \\
CV(\%) & 5,73 & 7,18 & 5,28
\end{tabular}

Médias seguidas de letras diferentes, na mesma coluna, diferem entre si pelo teste SNK a 5\% de probabilidade. T1 ração controle (sem adição de acidificante); T2 - ração controle + 0,5\% de ácido fumárico); T3 - ração controle + 0,5\% de ácido fumárico + 1\% de propionato de cálcio; T4 - ração controle + 0,5\% de ácido fumárico + 1\% de ácido lático; T5 - ração controle + 0,5\% de ácido fumárico + 0,5\% de propionato de cálcio + 0,5\% de ácido lático.

Não houve diferenças $(\mathrm{P}<0,05)$ entre os tratamentos em relação à altura do epitélio do duodeno, do jejuno e do íleo. A espessura do epitélio do duodeno foi maior $(\mathrm{P}<0,05)$ diante da inclusão de ácidos orgânicos em relação à dietacontrole, porém não houve alterações negativas na altura do epitélio do jejuno e do íleo. As alterações ocorridas na espessura do epitélio intestinal do duodeno não interferiram nos parâmetros de desempenho dos leitões na fase de creche.

As vilosidades intestinais do duodeno dos animais que receberam o tratamento controle apresentaram-se alongadas, digitiformes, com pouco polimorfismo, e foram classificadas como normais (Fig. 1). As vilosidades do duodeno dos animais que receberam os diferentes tratamentos apresentaram-se com aspecto típico do segmento, ou seja, alongadas, formato de folhas, poliformismo natural, comum aos diferentes segmentos do intestino delgado. Independentemente da utilização de ácidos orgânicos, a forma das vilosidades, neste experimento, está de acordo com a literatura.

Ao desmame, o intestino delgado de leitões geralmente sofre redução na altura das vilosidades e aumento na profundidade das criptas. Essas mudanças estão associadas à reduzida capacidade de absorção (Cera et al., 1988; Nabuurs, 1995; Pluske et al., 1996). Segundo Nabuurs (1995) e Pluske et al. (1996), mudanças semelhantes são observadas no epitélio do intestino delgado quando há redução no consumo voluntário de alimento e diarreia pós-desmame.

De acordo com Macari (1995), a densidade e o tamanho de vilosidades, bem como de microvilos, em cada segmento do intestino delgado, conferem características próprias a eles, e na presença de nutrientes a capacidade absortiva é proporcional à densidade e ao tamanho das vilosidades, ou seja, à área disponível para absorção. Dessa forma, as observações na morfologia intestinal sugerem que os ácidos orgânicos utilizados neste experimento não afetaram a absorção de nutrientes e o desempenho dos animais. Não foram observadas, em nenhum dos grupos, características de reação adversa, como inflamação severa, presença de muco ou fibrina e atrofia das vilosidades. Gomes et al. (2007) observaram que a associação de $1 \%$ de ácido fumárico aos ácidos butírico $(0,1 \%)$ e fórmico $(0,5 \%)$ causa prejuízos na altura do duodeno de leitões nas primeiras três semanas pós-desmame. 


\section{Gomes et al.}

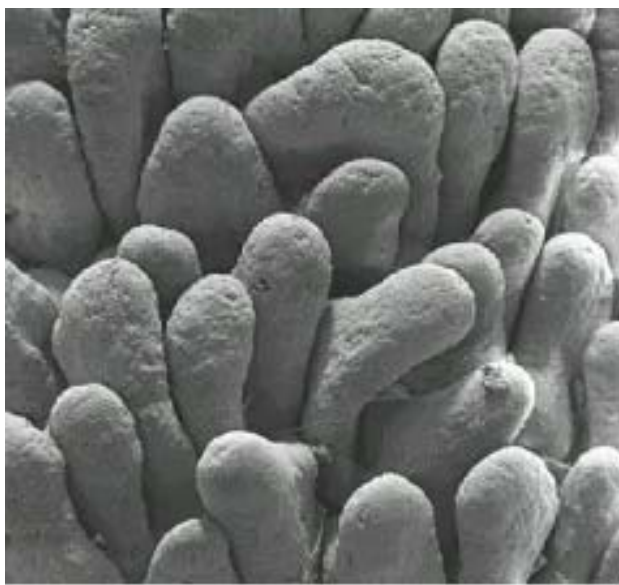

Tratamento 1

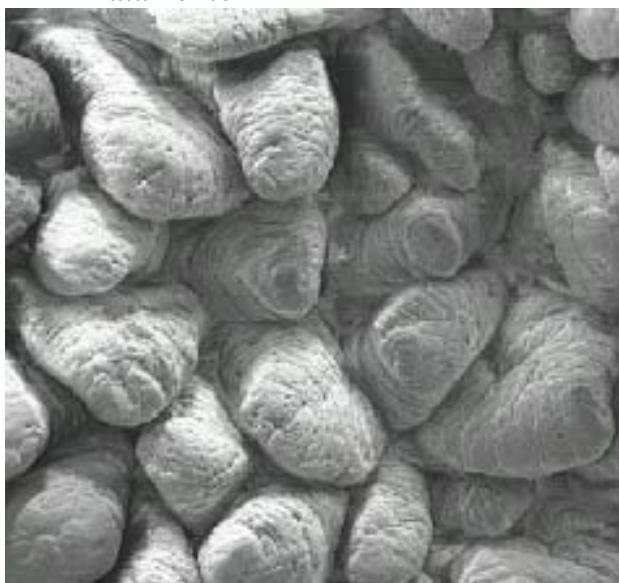

Tratamento 3

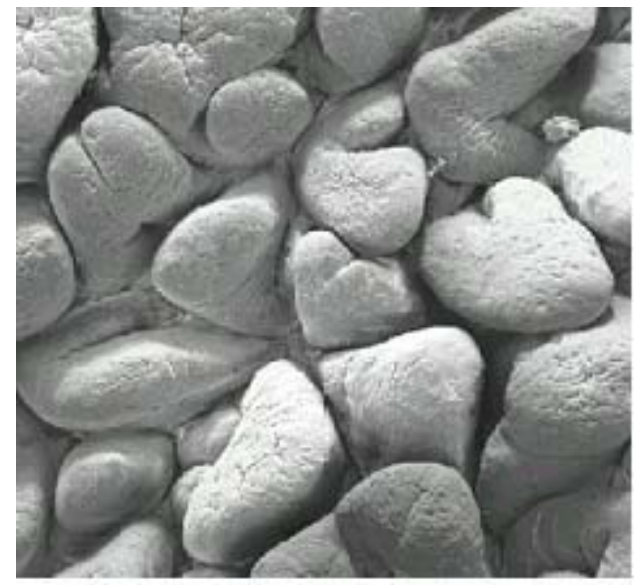

Tratamento 2

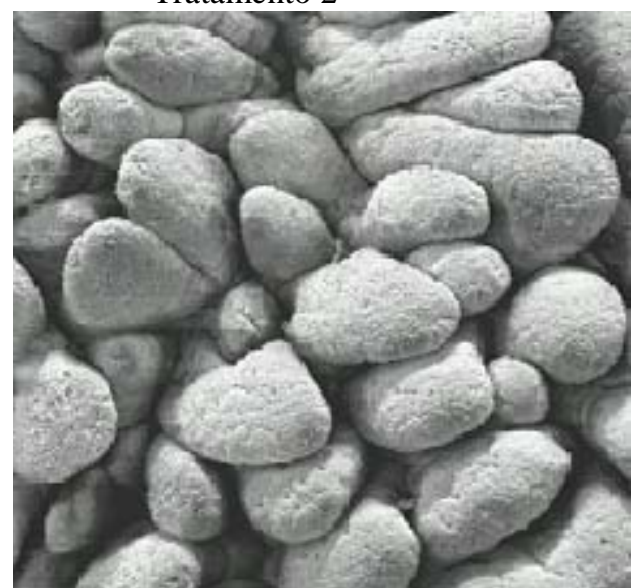

Tratamento 4

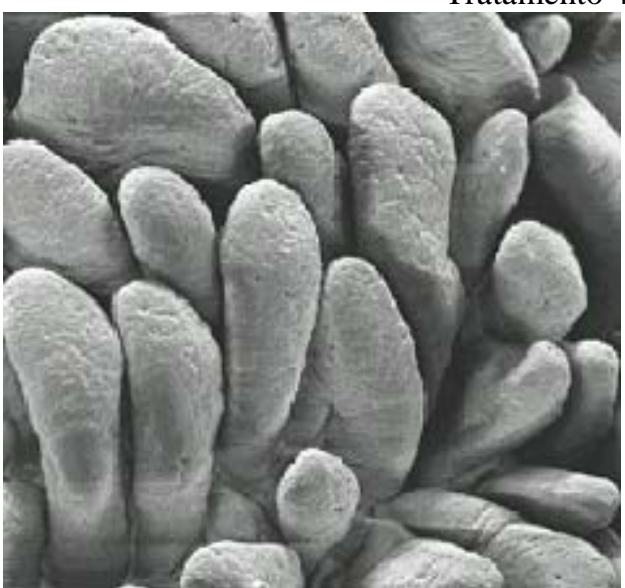

Tratamento 5

Figura 1. Eletronmicrografias de varredura das vilosidades intestinais do duodeno de leitões aos 36 dias de idade alimentados com ácidos orgânicos na ração durante toda a fase experimental. Aumento 100X.

T1 - ração controle (sem adição de acidificante); T2 - ração controle + 0,5\% de ácido fumárico); T3 ração controle $+0,5 \%$ de ácido fumárico $+1 \%$ de propionato de cálcio; T4 - ração controle $+0,5 \%$ de ácido fumárico + 1\% de ácido lático; T5 - ração controle + 0,5\% de ácido fumárico + 0,5\% de propionato de cálcio + 0,5\% de ácido lático. 


\section{CONCLUSÕES}

A utilização de ácido fumárico na concentração $0,5 \%$ e de sua combinação com os ácidos lático, na concentração $0,5 \%$, e propionato de cálcio não melhorou o desempenho e as características intestinais de leitões desmamados aos 15 dias.

\section{REFERÊNCIAS BIBLIOGRÁFICAS}

BOLDUAN, G; JUNG, H.; SCHNEIDER, R. BLOCK, J. et al. Influence of propionic and formic acids on piglets. J. Anim. Physiol. Anim. Nutr., v.59, p.72-78, 1988.

CERA, K.R.; MAHAN, D.C.; CROSS, R.F. Effect of age, weaning and postweaning diet on small intestinal growth and jejunal morphology in young swine. J. Anim. Sci, v.66, p.574-584, 1988.

EASTER, R.A. Acidification in diets for pigs. In: HARESIGN, W.Y COLE, D.J.A. (Eds.) Recent advances in animal nutrition. Butterworths: London, 1988. p.61-72.

GABERT, M.V.; SAUER, W.C. The effect of fumaric acid and sodium fumarate supplementation to diets for weanling pig on amino acid digestibility and volatile fatty acid concentrations in ileal digesta. Anim. Feed Sci. Technol., v.53, p.243-254, 1995.

GIESTING, D.W.; EASTER, R.A. Response of starter pigs to supplementation of corn-soybean meal diets with organic acids. J. Anim. Sci., v.60, p.1288-1294,1985.

GOMES, F.E.; FONTES, D.O.; SALIBA, E.O.S. et al. Ácido fumárico e sua combinação com os ácidos butírico ou fórmico em dietas de leitões recém-desmamados. Arq. Bras. Med. Vet. Zootec., v.59, p.1270-1277, 2007.

JUNQUEIRA, L.C.U.; JUNQUEIRA, L.M.M.S. Técnicas básicas de citologia e histologia. São Paulo: Universidade de São Paulo, 1983. 123p.

KYRIAKIS, S.C.; TSILOYIANNIS, V.K.; SARRIS, K. et al. The effect of cid lac dry in the feedon the metaphylaxis of post-weaning diarrhea syndrome of piglets. In: INTERNATIONAL PIG VETERINARY SOCIETY CONGRESS, 14., 1996, Bologna. Proceedings... Bologna: Faculty of Veterinary Medicine/ University of Bologna, 1996. p.430.
MACARI, M. Mecanismos de proliferação e reparação da mucosa gastrintestinal em aves. SIMPÓSIO DE COCCIDIOSE E ENTERITE, 1995, Campinas. Anais... Campinas: [s.n.], 1995p.

MARTINS, S.M.M.K.; FALLEIROS, F.T.; BRUNO, D.G. et al. Avaliação da combinação de produtos lácteos e acidificantes sobre o desempenho de leitões desmamados. In: CONGRESSO LATINO-AMERICANO DE SUINOCULTURA, 3., Foz do Iguaçu, 2006. Anais... Foz do Iguaçu, PR: [s.n.], 2006. p.567570.

MATHEW, A.G.A.L.; SUTTON, A.; SCHEIDT, D.M. et al. Effects of a propionic acid containing feed additive on performance and intestinal microbial fermentation of the weanling pig. In: INTERNATIONAL SYMPOSIUM ON DIGESTIVE PHYSIOLOGY IN PIGS. 5., 1991, Wageningen, Netherlands. Proceedings... Wageningen, Netherlands: Eaap Publication, 1991. p.464-469.

MAYES, P.A. Digestion and absorption. In: MURRAY, R.K.; GRANNER, D.K.; MAYES, P.A. et al. (Eds.). Harpers biochemistry, 22 ed. Norwalk, Conneticut: Appleton \& Lange, 1990. 580p.

MCCRACKEN, B.A.; GASKINS, H.R.; RUWEKAISER, P.J. et al. Diet-dependent and dietindependent metabolic responses underlie growth stasis of pigs at weaning. J. Nutr. v.125, p.28382845, 1995.

NABUURS, M.J.A. Microbiological, structural and functional changes of the small intesstine of pigs at weaning. Pig News Inf., n.16, p.93N-97N, 1995.

NUTRIENT requirement of swine. 10.ed. Washington, D.C.: National Academic of Sciences, 1998. 189p.

PARTANEN, K.H.; MROZ, Z. Organic acids for performance enhancement in pig diets. Nutr. Res. Rev., v.12, p.117-145, 1999.

PLUSKE, J.R.; WILLIAMS, L.H.; AHERNE, F.X. Villous height and crypt depth in piglets in response to increases in the intake of cows milk after weaning. Anim. Sci., v.62, p.145-158, 1996.

RAVINDRAN, V.; KORNEGAY, E.T. Acidification of weaner pig diets: a review. $J$. Anim. Food Agric., v.62, p.313-322, 1993. 

RISLEY, C.R.; KORNEGAY, E.T.;
LINDEMANN, M.D. et al. Effects of feeding organic acids on selected intestinal content measurements at varying times postweanig in pigs. J. Anim. Sci., v.70, p.196-206, 1992.

RISLEY, C.R.; KORNEGAY, E.T.; LINDEMANN, M.D. et al. Effects of organic acid with and without a microbial culture on performance and gastrointestinal tract measurements of weanling pigs. Anim. Feed Sci.Tech., v.35, p.259-270, 1991.

ROSTAGNO, H.S.; ALBINO, L.F.T.; DONZELE, J.L. et al. Tabelas brasileiras para aves e suínos: composição de alimentos e exigências nutricionais. Viçosa, MG: Universidade Federal de Viçosa, 2000. 141p.

SCIPIONI, R.; ZAGHINI, G.; BIAVATI, A. Researches on the use of acidified diets for early weaning of piglets. Zootec. Nutr. Anim., v.4, p. 201-218, 1978.

SILVA, M.C.; LIMA, J.A.F.; FIALHO, E.T. et al. Efeito da adição de acidificantes e suas combinações na alimentação de leitões desmamados sobre o desempenho. In: REUNIÃO ANUAL DA SOCIEDADE BRASILEIRA DE ZOOTECNIA, 39., 2002, Recife. Anais... Recife: SBZ, 2002. (CD-ROM).
SILVA, A.M.R.; BERTO, D.A.; LIMA, G.J.M.M. et al. Maltodextrina e acidificante em dietas de média complexidade: efeitos sobre o desempenho e a digestibilidade em leitões desmamados. In: CONGRESSO LATINOAMERICANO DE SUINOCULTURA, 3., 2006. Foz do Iguaçu. Anais... Foz do Iguaçu, PR: Editora, 2006. p.563-565.

SILVEIRA, A.M. Desempenho de leitões desmamados alimentados com rações contendo diferentes níveis de ácido fumárico. 2004. 53f. Dissertação (Mestrado) -Faculdade de Zootecnia e Engenharia de Alimentos, USP, São Paulo, SP.

SISTEMA de análises estatísticas e genéticas SAEG. Versão 8.0. Viçosa, MG: UFV, 2000. 142p.

TSILOYANNIS, V.K.; KYRIAKIS, S.C.; VLEMMAS, J. et al. The effect of organic acids on the control of porcine post-weaning diarrhea. Res. Vet. Sci., v.70, p.287-293, 2001. 